Cite this: RSC Adv., 2014, 4, 25063

\title{
Polyethyleneimine for copper absorption: kinetics, selectivity and efficiency in artificial seawater $\dagger$
}

Received 14th March 2014

Johan B. Lindén, ${ }^{a}$ Mikael Larsson, ${ }^{\text {a }}$ Bryan R. Coad, ${ }^{b}$ William M. Skinner ${ }^{a}$ and Magnus Nydén ${ }^{a}$

Accepted 27th May 2014

DOI: $10.1039 / c 4 r a 02223 h$

www.rsc.org/advances

Polyethyleneimine (PEI) is known to bind copper ions effectively and selectively. However, this is the first report on PEI-based materials for copper scavenging from ultra-low concentrations in seawater matrixes. The findings are relevant for water purification and sensing applications as well as extraction of copper from oceans.

The importance of effective detection, separation and selective removal of transition metal ions from contaminated waters is growing due to their toxic effects. ${ }^{1-4}$ Sources of contamination include metal plating, pickling in the steel industry, pigment industries and mining waste, to mention a few. ${ }^{5}$ In addition to the removal of metals from waste to meet regulations, recovery and reuse could offer economic benefits. ${ }^{6}$

There are also concerns about copper and zinc contamination passively released from antifouling paints in marinas and harbours. ${ }^{7,8}$ While the average copper concentration in seawater is around $3 \mathrm{ppb},{ }^{9}$ up to 22 and $114 \mathrm{ppb}$ have been reported in a marina in San Diego Bay $^{\mathbf{1 0}}$ and coastal water of India, ${ }^{\mathbf{1 1}}$ respectively.

Extraction of metals, especially uranium, from oceans has also attracted scientific interest over decades. Although the concentration of valuable metals in the oceans is typically very low, the vast abundance of water makes the total amount significant compared to minerals-based metals. The amount of energy needed to recover it seems, however, too high at present. $^{12}$

Polyethyleneimine (PEI) polymers are well known for their ability to bind metal ions, ${ }^{\mathbf{1 3 , 1 4}}$ with commercially available branched PEI commonly having primary, secondary and tertiary amine groups in approximately $1: 1: 0.7$ ratio. The branched PEI is the most efficient in binding copper and forms complexes

${ }^{a}$ Ian Wark Research Institute, University of South Australia, Mawson Lakes, SA, 5095, Australia. E-mail: larsson.mikael@gmail.com; Fax: +61-8-830-23493; Tel: +61-8-83023493

${ }^{b}$ Mawson Institute, University of South Australia, Mawson Lakes, SA, 5095, Australia $\dagger$ Electronic supplementary information (ESI) available: Experimental details, calculations, Tables S1-S6 and Fig. S1-S4. See DOI: 10.1039/c4ra02223h with a $\mathrm{N}$ : $\mathrm{Cu}$ ratio of $4-5.4^{4,15}$ PEI covalently attached to silica particles, effectively removes copper from $6 \mathrm{ppm}$ solutions at $\mathrm{pH}$ values ranging from $2-4 .^{6,16}$ Similar materials were reported to remove copper from mine wastewater containing copper (130 ppm), aluminium (40 ppm), manganese (210 ppm) and zinc (550 ppm) with some selectivity at $\mathrm{pH} 5 .^{5}$

PEI has also been suggested for copper sensing applications., ${ }^{\mathbf{4}, \mathbf{1 7}, 18}$ Wen et al. for instance developed a spectrophotometric method based on PEI in solution for binding $\mathrm{Cu}^{2+}$ with a detection limit of $566 \mathrm{nM}$ (36 ppb) and high selectivity compared to a variety of transition metal ions. ${ }^{4}$ However, the method was not applicable for solutions at $\mathrm{pH}>7$. Moreover the effect of other metal ions was not investigated.

Yuan et al., used hyperbranched PEI-coated silver nanoclusters together with a fluorescence quenching based technique to selectively detect copper. ${ }^{17}$ They reported an optimum selectivity at $\mathrm{pH} 4$ and a detection limit of $10 \mathrm{nM}(0.6 \mathrm{ppb})$ and reliable measurements over a wide $\mathrm{pH}$ range, varying ionic strength and temperatures. Like Wen et al., ${ }^{\mathbf{4}}$ the selectivity of copper was investigated for one metal ion at a time. To our knowledge no investigation has reported the effect of several other metal ions competing with copper for binding to PEI at ppb concentrations.

Based on some of the results presented in this publication we recently patented an antifouling technique comprising a coating that selectively binds to a specific metal ion naturally abundant in an aqueous environment (international (PCT) patent application PCT/AU2013/001416). In addition to antifouling, the results presented below suggest that it might be feasible to remove copper contamination in harbours and marinas where the concentrations are above water quality criteria. ${ }^{\mathbf{1 0}}$ For example, a copper contaminated marina located in southeastern San Diego bay contains $313000 \mathrm{~m}^{3}$ water with 22 ppb copper. ${ }^{10}$ With the technology presented here the concentration could be reduced, below chronic criteria (>3.1 ppb) of the California Toxic Rule, ${ }^{19}$ to $2 \mathrm{ppb}$ (equivalent to a reduction of $6 \mathrm{~kg}$ ) by using $137 \mathrm{~kg}$ of PEI (for calculations see $\mathrm{S} 3, \mathrm{ESI} \dagger)$. Although it may be of interest to further indicate the 
feasibility of mining copper from the oceans by similar calculations, it is to the authors' beliefs that control of elevated concentrations in contaminated marinas comprises a more realistic application due to both energy requirements and abundance of copper.

In this work we used branched PEI $\left(M_{\mathrm{n}} \sim 60000\right.$ and $M_{\mathrm{w}} \sim$ $750000)$ applied as very thin coatings on silicon wafers and subsequently cross-linked with glutaraldehyde (GA) by a method adapted from Tong et al. ${ }^{\mathbf{2 0}}$ (Scheme 1). The average dry layer thicknesses of the coatings were $7.9 \mathrm{~nm}$ (S.D. $1.1 \mathrm{~nm}, n=$ 32), as determined by ellipsometry (Table S2, ESI $\dagger$ ). The coating thickness could be easily tuned by varying the concentration of PEI in solution used in the spin coating process (Table S3, ESI $\dagger$ ). Only a slight increase in thickness was induced by GA crosslinking (Table S4, ESI $\dagger$ ). The samples were further characterised by atomic force microscopy (AFM), revealing a smooth surface and providing a second measure of coating thickness that correlated well with ellipsometry (Fig. S2, ESI $\dagger$ ).

Copper uptake started after immersing the coatings in artificial seawater or Milli-Q water, spiked with $\mathrm{CuSO}_{4}$ to achieve copper concentrations in the range 2 to $200 \mathrm{ppb}$. The metal content in the coatings was determined by X-ray photoelectron spectroscopy (XPS) and reported as the relative metal to nitrogen ratio, as calculated from XPS survey spectra (e.g. Fig. 1). We are aware that other studies have measured the metal ion uptake indirectly in the water phase..$^{\mathbf{5 , 6 , 1 6}}$ Here a direct method was instead applied via XPS analysis to acquire the elemental composition throughout the coating. This was possible as the coatings were thinner than the maximum analysis depth of the XPS. The coating thickness also provided an advantageous timeframe for study of sorption equilibrium. Further analysis by XPS to determine the oxidation state of the copper ions in the coatings showed that the copper loaded coatings contained

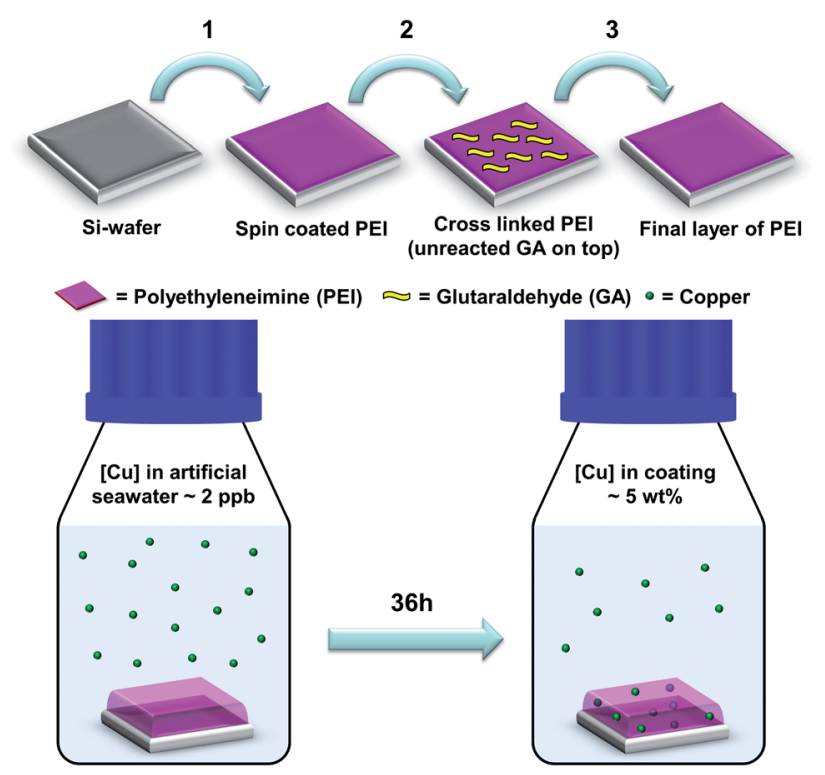

Scheme 1 Preparation of cross-linked PEI coatings and example of copper uptake from artificial seawater (for experimental details and calculations see $\mathrm{S} 1$ and $\mathrm{S} 2$ respectively, $\mathrm{ES} / \dagger)$.

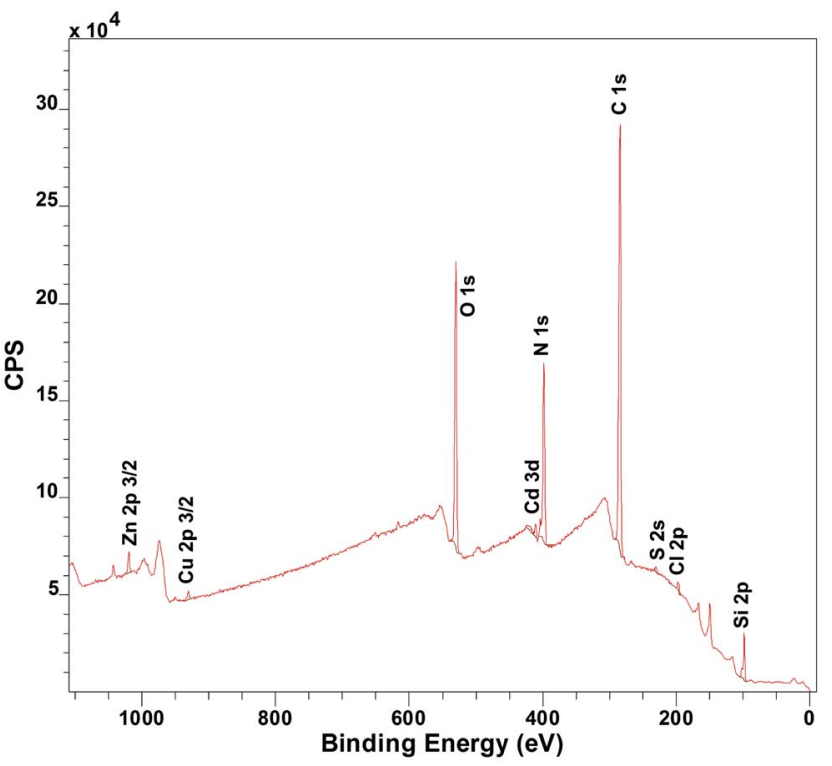

Fig. 1 Exemplifying XPS spectra of sample immersed for 15 minutes in artificial seawater $(\mathrm{pH} 8)$ with 12 different metal ions present at the same time: $\mathrm{Al}^{3+}, \mathrm{Cd}^{2+}, \mathrm{Co}^{2+}, \mathrm{Cr}^{3+}, \mathrm{Cu}^{2+}, \mathrm{Fe}^{2+}, \mathrm{Mn}^{2+}, \mathrm{Mo}^{6+}, \mathrm{Ni}^{2+}, \mathrm{Pb}^{2+}$, $\mathrm{V}^{3+}, \mathrm{Zn}^{2+} .\left[\mathrm{Me}^{2+}\right]=3 \mu \mathrm{M}\left(\left[\mathrm{Cu}^{2+}\right]=200 \mathrm{ppb}\right)$. Quantified peak areas of the metals and nitrogen were used to determine the relative atomic ratio of metal to nitrogen in the coating (see S6 for further details, ESI †े).

dominantly $\mathrm{Cu}$ (II) throughout the entire coating (Fig. S3 and Table S5, ESI $\dagger$ ). The coatings were moreover shown to be stable through dry layer thickness determination before and after immersion in the different solutions (Table S6, ESI $\dagger$ ). Shaking was shown to have insignificant effect on the copper uptake (Fig. S4, ESI $\dagger$ ).

A plateau was reached after four hours of immersion in artificial seawater at 200 ppb (Fig. 2(a)). At that plateau the ratio of nitrogen to copper suggests a coordination number of 7.9 (S.D. 0.7, $n=3$ ) which seems reasonable in comparison to the reported $\mathrm{N}$ : $\mathrm{Cu}$ ratio for $\mathrm{PEI}$ in solution of $4-5 .^{4,15}$ The copper content in the coating was estimated to $13 \mathrm{wt} \%$ (for calculations see S2, ESI $\dagger$ ). The sorption equilibrium was dependent of the concentration in solution and the solution volumes of the different concentrations were adjusted to contain the same excess of copper ions. For $20 \mathrm{ppb}$ the plateau was reached after 12 hours and for $2 \mathrm{ppb}$ the plateau was reached after 36 hours, where the copper content was estimated to 8 and 5 wt\% respectively (for calculations see $\mathrm{S} 2, \mathrm{ESI} \dagger$ ).

Investigations of the metal ion uptake of the coatings from a mixture of twelve different metal ions revealed very high specificity for copper after long immersion times (Fig. 2(b)). At short immersion times the coatings contained more zinc and to some extent cadmium. Surprisingly no other metal ions where detected. This showed that the binding kinetics for zinc was faster but copper binding was thermodynamically favoured.

Comparison of the copper uptake in different solutions showed that when other metal ions were present the rate of copper uptake was slower than when only copper ions were present in both Milli-Q water and artificial seawater (Fig. 2(c)). This could also be an indication of a competitive binding- 

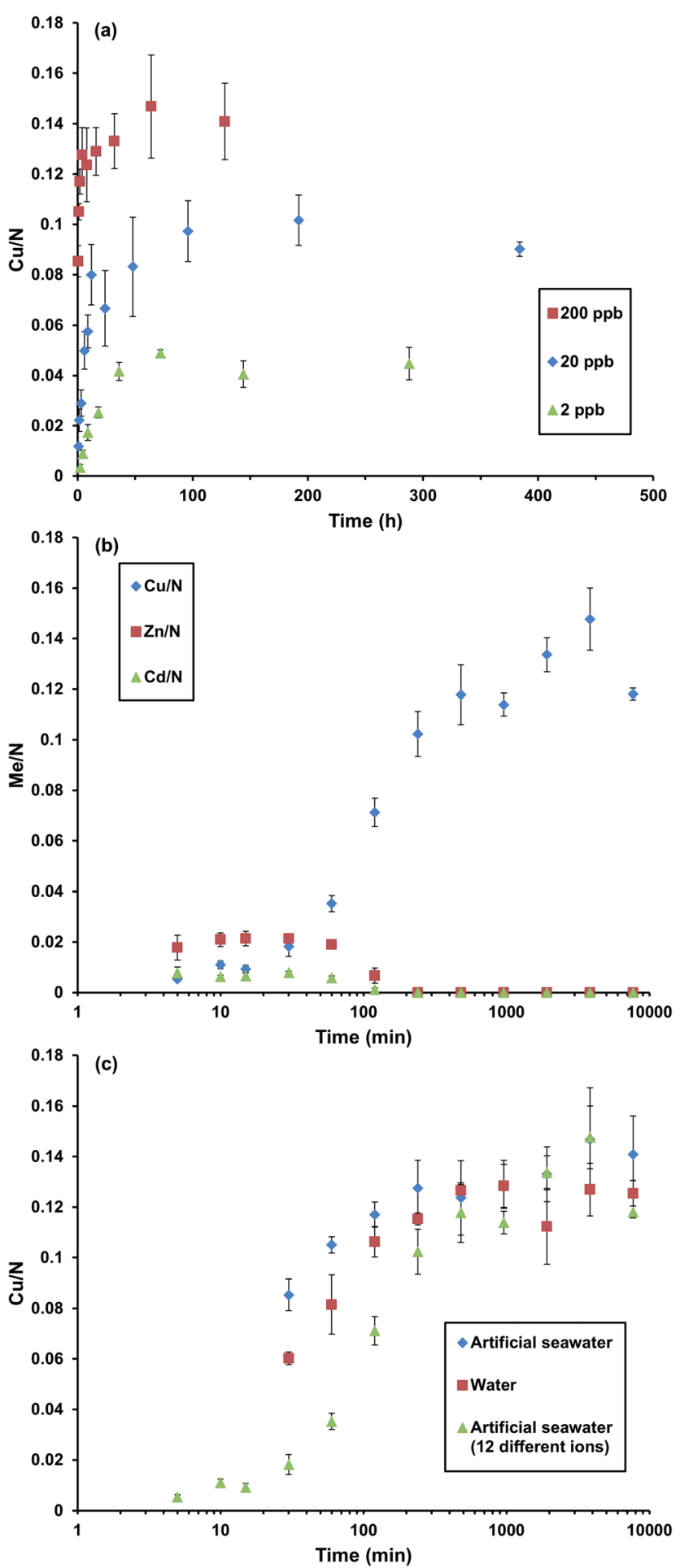

Fig. 2 Graphs showing metal uptake as of coatings over time. (a) Copper to nitrogen ratio as a function of time after immersion in artificial seawater $(\mathrm{pH} 8)$ for three different $\left[\mathrm{Cu}^{2+}\right]$. (b) Metal to nitrogen ratio as a function of time after immersion in artificial seawater $(\mathrm{pH} 8)$ with 12 different metal ions present at the same time: $\mathrm{Al}^{3+}, \mathrm{Cd}^{2+}, \mathrm{Co}^{2+}$, $\mathrm{Cr}^{3+}, \mathrm{Cu}^{2+}, \mathrm{Fe}^{2+}, \mathrm{Mn}^{2+}, \mathrm{Mo}^{6+}, \mathrm{Ni}^{2+}, \mathrm{Pb}^{2+}, \mathrm{V}^{3+}, \mathrm{Zn}^{2+} \cdot\left[\mathrm{Me}^{2+}\right]=3 \mu \mathrm{M}$ $\left(\left[\mathrm{Cu}^{2+}\right]=200 \mathrm{ppb}\right)$. (c) Copper to nitrogen ratio as a function of time after coating being immersed in different types of solutions. $\left[\mathrm{Cu}^{2+}\right]=$ $200 \mathrm{ppb}$. Error bars indicate deviation $(n=3)$. process taking place initially between copper, zinc and cadmium.

In conclusion, thin coatings of chemically cross-linked PEI were shown to accumulate as much as 13,8 and $5 \mathrm{wt} \%$ copper from 200,20 and $2 \mathrm{ppb}$ in artificial seawater, respectively. This makes PEI interesting for selective separation and purification as well as extraction of copper from oceans. From studies of mixtures of twelve transition metal ions, the coating was shown to be very specific towards copper after long immersion times. At short immersion times, the coatings contained more zinc. However, at longer times, zinc was replaced by copper, showing that the binding kinetics was faster for zinc, but with copper binding being thermodynamically favoured. Finally, it was shown that the rate of copper uptake was slower in the presence of other transition metal ions compared to neat copper in Milli$Q$ water or artificial seawater.

We acknowledge that this research has been financially supported by US DARPA (Grant number W911NF1310015) and ITEK Ventures Pty Ltd, the commercialisation arm of the University of South Australia. We also acknowledge that this work was performed in part at the South Australian node of the Australian National Fabrication Facility, a company established under the National Collaborative Research Infrastructure Strategy to provide nano and micro-fabrication facilities for Australia's researchers.

\section{Notes and references}

1 P. E. Duru, S. Bektas, Ö. Genç, S. Patir and A. Denizli, J. Appl. Polym. Sci., 2001, 81, 197.

2 E. Gaggelli, H. Kozlowski, D. Valensin and G. Valensin, Chem. Rev., 2006, 106, 1995.

3 N. G. Pekel and O. Güven, Colloid Polym. Sci., 1999, 277, 570.

4 T. Wen, F. Qu, N. B. Li and H. Q. Luo, Arabian J. Chem., 2013, DOI: 10.1016/j.arabjc.2013.06.013.

5 R. J. Fischer, D. Pang, S. T. Beatty and E. Rosenberg, Sep. Sci. Technol., 1999, 34, 3125.

6 S. T. Beatty, R. J. Fischer, D. L. Hagers and E. Rosenberg, Ind. Eng. Chem. Res., 1999, 38, 4402.

7 L. Kiaune and N. Singhasemanon, Rev. Environ. Contam. Toxicol., 2011, 213, 1.

8 K. Schiff, D. Diehl and A. Valkirs, Mar. Pollut. Bull., 2004, 48, 371.

9 R. R. Conry, Encyclopedia of Inorganic Chemistry, John Wiley \& Sons, Ltd, 2006, p. 1.

10 T. W. Biggs and H. D'Anna, Mar. Pollut. Bull., 2012, 64, 627.

11 C. K. Sekhar, S. N. Chary, K. C. Tirumala and V. Aparna, Acta Chim. Slov., 2003, 50, 409.

12 U. Bardi, Sustainability, 2010, 2, 980.

13 S. Kobayashi, K. Hiroishi, M. Tokunoh and T. Saegusa, Macromolecules, 1987, 20, 1496.

14 B. L. Rivas and K. E. Geckeler, Polymer Synthesis Oxidation Processes, Springer, 1992, p. 171.

15 T. D. Perrine and W. R. Landis, J. Polym. Sci., Part A-1: Polym. Chem., 1967, 5, 1993.

16 S. T. Beatty, R. J. Fischer, E. Rosenberg and D. Pang, Sep. Sci. Technol., 1999, 34, 2723. 
17 Z. Yuan, N. Cai, Y. Du, Y. He and E. S. Yeung, Anal. Chem., 2013, 86, 419.

18 F. Ungaro, G. De Rosa, A. Miro and F. Quaglia, J. Pharm. Biomed. Anal., 2003, 31, 143.
19 USEPA, California Toxics Rule, 40 CFR 131.38, Washington, DC, 2013.

20 W. Tong, C. Gao and H. Möhwald, Polym. Adv. Technol., 2008, $19,817$. 